\title{
OS ESTUDOS SOBRE LITERATURA INFANTIL E JUVENIL NO BRASIL E EM PORTUGAL: UMA ANÁLISE COMPARADA
}

Ana Margarida Ramos (Universidade de Aveiro) Eliane Debus (UFSC)

Resumo: $O$ artigo apresenta uma análise comparativa dos estudos teórico-críticos sobre literatura infantil e juvenil realizados no Brasil e em Portugal, a partir de três momentos: anos de 1960/1970, 1980/1990, 2000/2010, com o objetivo de mapear o seu desenvolvimento e refletir sobre as alterações, as continuidades e avanços verificados nestes períodos.

Palavras-chave: Literatura Infantil e juvenil, estudo comparativo, Portugal, Brasil.

Abstract: The article presents a comparative analysis of theoretical and critical studies on children's and young adult's literature carried out in Brazil and Portugal, in three different periods: 1960/1970, 1980/1990, $2000 / 2010$, in order to map the development of the theory produced and to reflect on the changes and the continuities in these periods.

Keywords: Children's and Young Adult's Literature, comparative study, Portugal, Brazil.

\section{ONDE SE EXPLICA OS CAMINHOS DA ESCRITA}

Escrito a quatro mãos, este texto apresenta uma análise comparativa dos estudos teórico-críticos sobre literatura infantil e juvenil (LIJ) realizados no Brasil e em Portugal, a partir de três momentos: anos de 1960/1970, 1980/1990, 2000/2010, com o objetivo de mapear o seu desenvolvimento e refletir sobre as alterações, as continuidades e os avanços 
verificados nestes períodos. Apesar de relativamente recentes, as reflexões com vista à caracterização da LIJ nestes dois países têm crescido e contribuído para a sua legitimação e reconhecimento social, fortalecendo a investigação, nomeadamente a acadêmica.

Os períodos acima enunciados permitem a identificação de trabalhos relevantes no estudo da LIJ, assim como das tendências dominantes das várias abordagens possíveis. Sejam elas de matriz histórica e/ou bibliográfica, analítica e crítica, ou realizadas a partir do ponto de vista da recepção leitora, as diferentes abordagens ilustram os desenvolvimentos que este universo foi conhecendo nas últimas décadas do século $X X$ e na primeira década do século XXI, período crucial para o desenvolvimento da LIJ e do seu estudo.

Os critérios para a escolha dos títulos analisados se devem ao relevo e repercussão em seus países, nomeadamente em estudos subsequentes, funcionando como referências incontornáveis para a investigação nesta área. Centraremos a nossa atenção em livros de autoria única, com exceção dos trabalhos das pesquisadoras brasileiras Marisa Lajolo e Regina Zilberman.

Este texto, ao descrever a investigação e a reflexão levada a cabo nos dois países, permitirá identificar os pontos em 
comum, assim como as não coincidências, que marcam as respectivas histórias, evidenciando momentos relevantes e possibilitando a comparação dos percursos. A partir da análise realizada, será possível projetar os desenvolvimentos futuros, bem como as trocas recíprocas entre os dois âmbitos, no que diz respeito aos estudos sobre a LIJ.

\section{A HISTÓRIA DOS ESTUDOS TEÓRICOS SOBRE LIJ: TRÊS MOMENTOS}

Escolhemos o recorte temporal nos anos de 1960/1970, 1980/1990 e 2000/2010 porque teríamos estudos comparativos, já que em Portugal as pesquisas sobre LIJ iniciam na década de 1970. No entanto, faz-se necessário abrir um parêntese e evidenciar os trabalhos anteriores a esta data publicados no Brasil e que, por certo, foram fundantes para pesquisas posteriores e repercutem nestas.

No Brasil, os estudos sobre literatura infantil recebem atenção a partir da promulgação, em janeiro de 1957, da Lei 3.739, que cria a obrigatoriedade de estudos teóricos e práticos sobre literatura infantil no currículo das normalistas. Ou seja, constata-se que a partir do momento em que a literatura infantil se torna disciplina do currículo de formação dos professores que atuarão com crianças do então ensino primário, o tema esteve 
presente nos manuais de ensino e em capítulos de livros a eles dirigidos, como se verifica na pesquisa realizada por Fernando Rodrigues Oliveira (2010).

Em sua pesquisa, Oliveira (2010) trouxe à tona o levantamento de manuais e capítulos de livros que discutem teoricamente a LIJ no período circunscrito de 1920 a 1990, elencando a produção de 23 autores, sendo 9 de manuais e 14 de capítulos de livros, argumentando que os manuais específicos e escritos de forma integral sobre o tema se dão somente a partir da década de 1950.

O Compêndio de literatura infantil ${ }^{1}$, de Bárbara Vasconcelos de Carvalho, datado de 1959, é elencado como o primeiro livro em sua categoria por ser "elaborado de acordo com os programas oficiais de ensino" (OLIVEIRA, 2010, p.41). Professora de Língua Portuguesa do Estado de São Paulo na década de 1950, a produção da autora se solidificou não somente com um manual para estudantes do 3으 ano normal, mas constitui uma referência para a história da literatura infantil brasileira ao abordar vários aspectos históricos e analíticos da LIJ. Na introdução do livro, ela argumenta sobre as pretensões da publicação:

1 Vale destacar que na década de 1970 o livro é ampliado e reformulado recebendo um novo título: Literatura infantil: estudos (1973) e, na década de 1980, uma nova reformulação e um novo título - Literatura infantil: visão histórica e crítica (1982). Segundo estudos de Oliveira (2010), os livros da década de 1970 e 1980, embora atualizados, têm como gérmen o Compêndio escrito na década de 1950. 
Num livro escolar, como é este, apresentamos um programa que traga uma visão panorâmica do assunto, a fim de orientar os alunos para as suas aulas e o desenvolvimento de suas teses. Não pretendemos fazer outra coisa senão oferecer-lhes material sistematizado e condensado, para facilitar-lhes o estudo, cabendo, então, ao professor orientá-los e dirigi-los. (CARVALHO, 1961, p. 9-10)

Neste mesmo período, os livros dos Professores Antônio d'Ávila, Literatura infanto-juvenil (1958), e Nazira Salem, Literatura infantil ${ }^{2}$ (1959), somam as publicações comprometidas com a formação dos professores que atuarão com as crianças.

Embora Problemas da Literatura infantil, de Cecília Meireles, não se inscreva na categoria dos títulos analisados por Oliveira (2010), cabe trazê-lo aqui como um dos primeiros trabalhos sobre o tema. Resultado de três conferências proferidas pela educadora Cecília Meireles, os textos conhecem a publicação em livro em 1951. O livro não se constitui num Panorama da Literatura, mas, em seus 19 pequenos capítulos, ela aborda temas interessantes como a definição do gênero, a preocupação com o leitor criança, a qualidade na literatura para infância, espaços de mediação leitora, como a biblioteca, além de analisar alguns títulos

2 O livro foi reeditado em 1970 com o título História da Literatura infantil. 
que comporiam um acervo básico para infância, como Alice no País das Maravilhas, de Lewis Carroll. Comprometida com a formação do leitor criança, ela argumenta que "Um livro de Literatura Infantil é, antes de mais nada, uma obra literária. Nem se deveria consentir que as crianças frequentassem obras insignificantes, para não perderem tempo e prejudicarem seu gosto" (MEIRELES, 1984, p.123).

Este preâmbulo para adentrarmos nos períodos deste estudo se fez necessário para apresentarmos, mesmo que de forma breve, a inserção de publicações brasileiras sobre o tema em questão. Vale lembrar que seus autores estavam vinculados e comprometidos com a formação de professores e muitos destes títulos, alguns revistos e atualizados, circulam ainda hoje no Brasil como referência.

\section{PRIMEIRO MOMENTO: ANOS DE 1960/1970}

Em 1968, vem a público o livro Literatura infantil brasileira ${ }^{3}$, do jornalista e historiador Leonardo Arroyo. Obra de cunho historiográfico, levava um subtítulo que apontava o seu fim "Ensaio de preliminares para a sua história e suas fontes". A publicação apresenta-se dividida em seis capítulos que

3 Literatura Infantil brasileira, de Leonardo Arroyo, teve até hoje três edições. A primeira, de 1968, e a segunda, de 1988, foram editadas pela Melhoramentos e, em 2011, pela UNESP. Segundo a Apresentação de Maria do Rosário Longo Mortatti, “(...) a repercussão do livro ao longo dos seus 43 anos vem confirmar muitas das 'profecias' relativas a sua utilidade e as suas possibilidades de circulação, assim como evidencia muitos caminhos de estudo e pesquisa ainda inexplorados, como os sugeridos ou os sequer vislumbrados por seu autor" (ARROYO, 2011, XII). 
versam sobre a origem, aspectos conceituais e temáticos, a literatura oral e os elementos nacionais e regionais em sua composição, em particular na sua fase embrionária; e as transformações culturais com a vinda da família real portuguesa para o Brasil (1808).

Motivado provavelmente pela sua formação jornalística, o autor dedica um capítulo à imprensa escolar e infantil, elencando as atividades jornalísticas, nos jornais e revistas, em 15 estados do sul ao norte do Brasil, dedicadas a infância e juventude, com destaque para a Revista Tico-Tico, periódico criado pelo mineiro Luís Bartolomeu de Sousa e Silva que circulou entre as crianças brasileiras com regular periodicidade entre os anos de 1905 e 1957.

No ano mesmo de 1968, Maria Antonieta Antunes Cunha publica Como Ensinar Literatura Infantil que tinha como público alvo estudantes do Curso Normal. O livro encontrase dividido em sete unidades estruturadas didaticamente em três tópicos: noções sobre o tópico a ser estudado, estudo do texto e sugestões do trabalho (organizado a partir de um questionário que varia o número de questões conforme a unidade). Atualizado e ampliado, o livro ganha nova roupagem em 1983 com o título Literatura Infantil: teoria \& prática, sem perder, no entanto, o seu caráter formativo. 
Passa a dividir-se em oito unidades com estrutura próxima a anterior: aspecto teórico, texto de apoio e sugestões de trabalho. Nas pesquisas de Oliveira (2010), este manual lidera o número de reedições, somando entre os anos de 1983 a 2003 o número de 18 edições.

Criança é criança: literatura infantil e seus problemas, de Maria Lúcia Amaral, publicado em 1971, é o resultado de cursos que a autora ministrou no Museu Histórico Nacional e tinha como "público alvo professores, bibliotecárias, normalistas e mães" (AMARAL, 1974, p.7). Dividindo-o em 10 capítulos, a autora desenvolve temas diversos: caracterizando o livro para crianças, e as marcas do fantástico e folclórico nesse gênero, sistematizando alguns gêneros como poesia, teatro, história em quadrinhos, jornal. Neste item a autora jornalista expõe os seus 12 anos de experiência no suplemento infantil do Diário de Notícias "O Calunga".

Este período, marcado pela diversidade de formação de seus autores, tem estreito vínculo com os estudos que estavam sendo desenvolvidos nas universidades brasileiras (em nível de mestrado e doutorado) - muitas das publicações da década de 1980 estavam sendo gestadas -, bem como as primeiras inserções da Literatura Infantil como disciplina optativa no currículo de formação 
dos professores nos cursos de Graduação. Maria Antonieta Cunha, na Universidade Federal de Minas Gerais (UFMG), e Nelly Novaes Coelho, na Universidade de São Paulo (USP), introduzem a literatura infantil na grade curricular dos cursos de suas respectivas universidades entre o final da década de 1960 e início de 1970.

Por outro lado, a criação de instituições como a Fundação Nacional do Livro Infantil e Juvenil ${ }^{4}$ (FNLIJ/ 1968) vai desempenhar papel relevante para a fomentação da produção literária para crianças, "organizando programas de promoção de leitura, instituindo prêmios que ressaltam a produção editorial nessa área e participando de projetos de divulgação do livro, que se estendem por todo o País, a partir da década de 1980" (DEBUS, 1996).

A Lei de Diretrizes e Bases da Educação 5.692/71, ao instituir a ampliação do nível de escolaridade, acelera também o processo de fomento do gênero ao recomendar a leitura de autores nacionais para os leitores em formação (na época ensino de primeiro grau). Entre essas décadas ocorre fenômeno de acréscimo da produção denominada por muitos estudiosos como o "Boom" da literatura infantil.

4 Seção brasileira do International Board on Books for Young People - IBBY, a FNLIJ, "é uma instituição de direito privado, de utilidade pública federal e estadual, de caráter técnicoeducacional e cultural, sem fins lucrativos, estabelecida na cidade do Rio de Janeiro" com a missão de "promover a leitura e divulgar o livro de qualidade para crianças e jovens, defendendo o direito dessa leitura para todos, por meio de bibliotecas escolares, públicas e comunitárias". (http://www.fnlij.org.br/site/o-que-e-a-fnlij.html). 
Soma-se a essa efervescência a criação de Associações, grupos de pesquisas e eventos, em sua grande maioria vinculados a academia, que começam a tematizar a importância da leitura, como o Congresso de Leitura do Brasil (COLE), inaugurado em 1979.

Nos anos 70 do século XX, cresce, também em Portugal, o interesse pelo estudo e pela divulgação da LIJ. As alterações verificadas no ensino, com o alargamento da escolaridade mínima obrigatória, bem como uma ligeira abertura política do regime ditatorial poderão explicar a crescente atenção pelas publicações dedicadas ao público mais jovem. De cariz descritivo e bibliográfico, respectivamente, as publicações de Lemos (1972) e de Guimarães de Sá (1974; 1977) ilustram essa tendência. No caso de Esther de Lemos, trata-se de um volume muito breve, inserido numa coleção editada pelo Ministério da Educação Nacional, que reuniu um conjunto de conferências sobre o tema proferidas na Biblioteca Nacional acompanhadas de uma exposição ${ }^{5}$. Apesar da brevidade da reflexão, o estudo chama a atenção para a especificidade da LIJ e para o seu aparecimento tardio no contexto português, distinguindo-a claramente da produção de cariz pedagógico

5 De acordo com Natércia Rocha, "em 1972, a Direcção Geral de Educação Permanente organiza um 'ciclo de conferências sobre literatura infantil' no edifício da Biblioteca Nacional. (...) Em 1973, é a literatura juvenil que serve de tema a novo ciclo (...). Os textos das conferências foram publicados pela Direcção Geral de Educação Permanente" (ROCHA, 1984, p. 144). 
e moralizador. A abordagem panorâmica abrange as últimas décadas do século XIX, com especial relevo para a geração de 70, até aos anos 30 do século XX e não deixa de sublinhar as contradições entre a reflexão teórica, que defendia uma literatura de qualidade literária destinada a crianças, e a prática, às vezes dos mesmos autores, de uma literatura distante dos interesses (e às vezes competências de leitura) seu público-alvo. Outra reflexão, assaz pertinente, prendese com a confusão entre literatura para a infância e infância como tema literário, originando publicações que, tendo as crianças como protagonistas, não são verdadeiramente pensadas para o público infantil (LEMOS, 1972, p.15). Refirase que, na mesma coleção, um ano depois, vinha a lume $A$ Literatura Juvenil em Portugal (1973), de João David Pinto Correia $^{6}$, publicação decorrente de conferência homónima. O estudioso destaca a "pobreza" (CORREIA, 1973, p.11) da produção literária destinada aos jovens, tal como dos estudos que a contemplam, pese embora reconhecer-lhe um "papel importantíssimo" (CORREIA, 1973, p.11) na formação

6 Este autor voltará ao tema, com a publicação, em 1978, do volume Literatura Juvenil / Paraliteratura, onde distingue a literatura infantil da juvenil baseando-se não só no critério da idade dos destinatários, mas também na aproximação da literatura juvenil ao universo paraliterário, justificando esta posição com a sua "maior restrição dos códigos" (CORREIA, 1978, p. 30), definindo-a como consistindo "fundamentalmente em práticas paraliterárias de 'imaginação' que podemos caracterizar como próximas da 'literatura de massas'" (CORREIA, 1978 , p. 36), circunscrevendo-a ao universo das séries e das coleções de tipo codificado e repetitivo, ainda que preveja, com o seu conceito de "aspiração literário-normativa", a existência de obras que "garantem uma organização (...) literária do discurso" (CORREIA, 1978, p. 50), que designará, posteriormente, como "realizações acertadas" (CORREIA, 1978, p. 51). 
dos jovens, não só em termos dos valores, mas também da sensibilidade estética, por exemplo. A análise destaca a exígua produção nacional e a aposta na edição de traduções, percorrendo os distintos modos e gêneros literários.

Domingos Guimarães de Sá distinguiu-se como bibliotecário, tendo sido pioneiro na dinamização de uma secção infantil e juvenil na Biblioteca Pública de Braga. O seu interesse e a sua atividade nesta área levaram-no à realização de várias atividades relacionadas com a sua promoção, no contexto da leitura pública. Os seus Catálogo de Literatura Infantil e Catálogo de Literatura Juvenil, cujas primeiras edições datam de 1974 e 1977, respectivamente, têm relevo documental, procedendo ao levantamento, tão exaustivo quanto possível, da produção nesta área, na esteira do trabalho pioneiro de Henrique Marques Júnior que, em 1928, dera à estampa Algumas achegas para uma bibliografia infantil. O labor de Guimarães de Sá será desenvolvido na década seguinte, com a publicação da 2 a edição do catálogo. A fechar a década, destaque-se a publicação de Alice Gomes, A Literatura para a Infância (1979), aproximação de cariz historiográfico da produção destinada aos mais novos, visando a sua caracterização e a evolução ao longo do tempo, decorrente das suas funções 
como formadora de professores nos cursos do Magistério Primário, onde era responsável pelo ensino de uma cadeira de Literatura Infantil.

\section{SEGUNDO MOMENTO: ANOS DE 1980/1990}

A década de $1980^{7}$, no Brasil, constitui-se como um dos momentos de grande profusão de publicações para crianças e, por consequência, de reflexões teóricas sobre o tema, em sua grande maioria vinda do espaço acadêmico universitário.

Em 1981, Nelly Novaes Coelho publica Literatura Infantil: história - teoria - análise (das origens orientais ao Brasil de hoje $)^{8}$, que apresenta a literatura nos aspectos históricos, não deixando de analisar os principais títulos literários universais para infância e em circulação no Brasil.

Na mesma década de 1980, Nelly Novaes Coelho publica o Dicionário crítico da literatura infantil e juvenil ${ }^{9}$, trabalho individual e de fôlego, constrói em forma de verbetes a

7 Na década de 1980 também surgem as publicações resultantes de dissertações de mestrado e teses de doutorado, embora apresentando trabalho sobre temas específicos: Usos e abusos da Literatura na escola: Bilac e a literatura escolar na República Velha, de Marisa Lajolo, resultado da tese defendida na USP, e $O$ texto sedutor na literatura infantil, de Edmir Perroti, resultado da Dissertação de Mestrado na USP, consolidam-se como livros de referência para os estudos da área.

8 Reeditado em 2000, pela editora Moderna, com o título Literatura infantil: teoria, análise, didática.

9 Em 1995, a autora apresenta o livro reformulado e atualizado, contemplando os escritores e títulos publicados entre os anos de 1808 e 1990, resultando no verbete de 784 autores e a apresentação de 3508 títulos. Trata-se de uma obra de referência. Dividido em duas partes precursores, que engloba o período de 1808 a 1920, e literatura infantil/juvenil brasileira, que circunscreve a produção de 1920 a 1990. 
biografia de escritores e breve análise de seus títulos, no período contemplado - os anos de 1882 a 1982 - usando como critério o período circunscrito ao ano de nascimento de Monteiro Lobato e a atribuição do Prêmio Hans Christian Andersen à escritora brasileira Ligia Bojunga Nunes.

Regina Zilberman lança, em 1981, A literatura infantil na escola - resultado de escritas produzidas entre os anos de 1979 e 1980. O livro subdivide-se em quatro capítulos que tratam de questões gerais e análises de obras específicas.

Zilberman e Lajolo, sem sombra de dúvidas, contribuíram e têm contribuído sobremaneira para os estudos da LIJ, em particular, no tema aqui proposto, com o livro Literatura infantil brasileira: histórias e histórias que teve sua primeira edição em 1984. Título marco nos estudos da área, dividido em seis capítulos, é uma cronologia histórico-literária onde as autoras compõem um mosaico da produção literária para a infância desde o seu surgimento na Europa, aos primeiro títulos brasileiros e fazendo esse levantamento até a década de 1980.

O trabalho conjunto reaparece em Um Brasil para crianças para conhecer a literatura infantil brasileira. As autoras dividem a obra em cinco capítulos sendo que quatro se referem aos períodos tratados por elas (1890-1920; 
1920-1945; 1945-1965; 1965-1980), contextualizando cada período no panorama histórico da literatura como um todo e demais produções culturais, e introduzindo fragmentos das obras mais significativas (visão documental). Datado de 1984, Introdução à literatura infantil e juvenil, de Lúcia Pimentel Góes, é direcionado editorialmente aos cursos de formação específica de 2‥ Grau para o Magistério, com o selo "Manuais de Estudo", da editora Pioneira. Dividido em quatro partes, a autora levanta questões importantes sobre a literatura infantil, entre elas aspectos relativos a função, características e critérios para a escolha dos livros para crianças, histórico da literatura infantil, tipologia das narrativas - dos contos de fadas tradicionais aos contos de fadas modernos.

Ainda nesta década, Glória Pondé traz a público o livro $A$ arte de fazer artes: como escrever histórias para crianças e adolescentes, que articula a produção atualíssima da época e a sua relação de circulação e recepção, sem, no entanto, esquecer o viés histórico que serve como pano de fundo ${ }^{10}$.

A década de 1990 marca a inserção definitiva da literatura infantil como material de pesquisa acadêmica nos Programas de Pós-Graduação em Letras. Nadia Gotlib (Apud HOLLANDA,

10 Na mesma década a autora publica, com Eliana Yunes, Leitura e leituras da Literatura infantil (1988), ampliando a reflexão sobre a recepção e os títulos de análise. 
1994) ${ }^{11}$, em documento do início da década, avalia três principais grupos emergentes na área de Letras, elencando a literatura infanto-juvenil como um deles.

Em Portugal, na década de 1980, para além das publicações de cariz bibliográfico, na esteira do que já vinha sendo editado anteriormente, assistimos à edição dos primeiros textos assumidamente panorâmicos da evolução histórica da LIJ portuguesa.

A segunda edição do catálogo bibliográfico de Guimarães de Sá, de 1981, reintitulado A Literatura infantil em Portugal. Achegas para a sua história inclui uma relevante "Nótula sobre o conceito de literatura infantil", da autoria de Vítor Manuel de Aguiar e Silva. Apesar de muito breve, as suas implicações são inúmeras, sobretudo pelo facto de ser escrita por um dos mais conceituados teóricos da literatura em Portugal, com especial incidência no estudo do texto literário canônico. A atenção que dedica ao texto literário para a infância, reclamando a sua "função relevantíssima" (SILVA, 1981, p.14), enumerando um longo conjunto de potencialidades e defendendo o seu estudo e valorização, teve um efeito legitimador assinalável.

11 As três seriam narrativas feitas por mulheres, narrativas africanas e narrativas infantojuvenis: "São aquelas que, até pouco tempo, foram identificadas como áreas marginais, não consideradas, ou quase não consideradas, legítimas pela historiografia canônica, e cujos produtos foram tradicionalmente definidos como gêneros 'menores' na medida em que se apoiavam em literaturas orais, correspondência, narrativas populares, cuja 'qualidade' era sistematicamente posta em questão pela crítica literária” (HOLLANDA, 1994, p. 453). 
A História da Literatura Infantil Portuguesa, de Maria Laura Bettencourt Pires, publicada em 1983, situa as suas origens em tempos bem mais distantes do que o século XIX, incluindo na análise, para além das obras especificamente dedicadas às crianças, textos que as crianças ouviam ou liam, incluindo livros de cariz formativo (para além dos de entretenimento). Organizada cronologicamente por capítulos e, em cada capítulo, por gêneros, é essencialmente um trabalho descritivo, com análise escassa dos títulos e pouco relevo na contemporaneidade, ainda que com antecedentes relevantes.

A abordagem de Natércia Rocha, publicada pela primeira vez em 1984, mas sucessivamente editada, revista e aumentada, até 2001, tornou-se incontornável para toda a investigação subsequente. Simultaneamente clara e acessível, sem deixar de ser completa e profunda, não só dá conta das publicações marcantes no domínio da LIJ portuguesa, como procede à sua análise temáticoideológica e formal, estabelecendo uma linha evolutiva desde o final do século XIX. As suas reflexões, que incluem textos e ilustrações, são enquadradas pelo contexto histórico (político, social e cultural) do país, o que aproxima esta História da Literatura para Crianças de publicações congêneres que se dedicaram ao estudo da produção para 
adultos, reconhecendo-Ihe interesse, validade e, sobretudo, relevância do ponto de vista da investigação e da reflexão. A sua análise contempla igualmente processos de promoção e divulgação da LIJ, revelando particular atenção em relação às novidades, nomeadamente em termos de gêneros e tendências. A autora não passa ao lado da LIJ em língua portuguesa, nomeadamente a brasileira, considerando já as emergentes literaturas africanas de países como Angola e Moçambique. Os fatores de legitimação da LIJ, como os prêmios e/ou o reconhecimento internacional são também alvo de atenção e reflexão. As apostas que enuncia em termos de autores e seu desenvolvimento acabaram por se revelar certeiras, como aconteceu com Álvaro Magalhães, por exemplo, ou Alice Vieira.

Mas o verdadeiro salto qualitativo da investigação da LIJ em Portugal, iniciada por Natércia Rocha e pelo seu trabalho pioneiro, será dado já na década de 90, por uma geração de investigadores que, na sua maioria, ainda conviveram com ela, como José António Gomes, figura tutelar dos estudos contemporâneos sobre a literatura para crianças.

Da sua autoria vieram a lume, na década de 90, vários estudos, sendo mais relevante, no âmbito desta análise, a publicação de Para uma História da Literatura Portuguesa para a Infância e Juventude (1998), onde o autor procura 
proceder à atualização das panorâmicas históricas de Esther de Lemos, Maria Laura Bettencourt Pires e Natércia Rocha, já analisadas anteriormente. Trata-se de um volume breve, de cerca de 100 páginas, complementado com ilustrações coloridas que reproduzem capas de alguns livros marcantes e um índice cronológico que lista, pela data da primeira edição, todos os livros de LIJ referidos, onde é dada especial atenção aos seus desenvolvimentos no século $X X$, em particular na segunda metade. A análise das obras referidas, mesmo se breve, dá conta dos seus principais traços ideotemáticos, bem como do registo, linguagem e inovação face ao seu tempo. Característica deste autor é a sistematização do contexto histórico e político, bem como do seu relevo na produção literária para a infância, numa clara aproximação à escola marxista. No contexto português, em particular do século $X X$, sob a vigência do Estado Novo e do seu regime ditatorial, esta leitura reveste-se de particular importância. A acuidade da análise, fortemente ancorada nos estudos literários, é outro aspeto marcante, dada a formação acadêmica do autor, aspecto que também singulariza o seu trabalho face aos seus antecessores, oriundos do universo da pedagogia e da educação e pensando a literatura para a infância como instrumento pedagógico e formativo. 
Do conjunto de volumes que na década de 1990 foi dedicado a aspetos parcelares da LIJ portuguesa, quase todos na mesma coleção (Costa, 1992; Veloso, 1994; Traça, 1992; entre outros), em resultado de um conjunto de teses de mestrado realizadas na Universidade Nova de Lisboa, destaca-se a reflexão de cariz teorizante de Américo António Lindeza Diogo (1994), Literatura Infantil. História, Teoria, Interpretações. A questão do estatuto da LIJ, mas também dos seus usos e rótulos, gira, sobretudo, em torno das relações entre as dimensões formativa e estética, mas também engloba o seu circuito, predominantemente adulto. Apesar de alguma fragmentação na formulação ${ }^{12}$ das considerações, que assumem um registro questionador, motivando a reflexão, são notórios os esforços de cruzamento de um conjunto abrangente de pontos de vista sobre a expressão literária definida como infantil, dando conta também da sua evolução e dos fatores sociais, culturais e até econômicos que dialogam com este fenômeno.

Antes do final da década, veja-se a publicação de Literatura para Crianças e Jovens em Portugal (1998), de Garcia Barreto, onde o autor reflete não só sobre o conceito e o estatuto da LIJ, dando conta da sua evolução, como procura dar conta da

12 O volume organiza-se em capítulos que depois aparecem divididos em parágrafos numerados não titulados, às vezes com exígua continuidade entre si. 
produção literária que às crianças e aos jovens vinha sendo destinada, sem esquecer a imprensa. Veja-se a novidade relativa à introdução de um capítulo sobre as relações da LIJ com a internet, fenômeno que, à altura, começava a suscitar alguma curiosidade e interesse. Mais de metade do volume é dedicada à apresentação de fichas de cariz biobibliográfico de autores, trabalho que Garcia Barreto desenvolverá posteriormente e que conduzirá à edição do Dicionário de Literatura Infantil Portuguesa (2002), a que voltaremos.

Em 1999, Glória Bastos publica a sua Literatura Infantil e Juvenil, um volume de cariz didático, com chancela da Universidade Aberta, que acabaria por se tornar no "manual" da disciplina com o mesmo nome em muitas instituições de ensino superior portuguesas. Destinado à formação à distância dos alunos da Universidade que o edita, este livro tem como principais qualidades a sua clareza e acessibilidade, para além de uma organização que facilita a leitura.

\section{TERCEIRO MOMENTO: ANOS DE 2000/2010}

O ano de 2000 é inaugurado com o coroamento da produção literária da escritora brasileira Ana Maria Machado, que ganha o prêmio Hans Christian Andersen, bem como da produção brasileira como um todo que se sobressai em número e qualidade estética. 
A primeira década do século XXI também confirma o crescente interesse de pesquisadores brasileiros pela LIJ e, por consequência, uma extensa publicação na área. Uma das características deste período são os trabalhos escritos coletivamente, em particular as organizações temáticas. O Grupo de pesquisa do Ceale (UFMG), por exemplo, publica, desde 1999, sistematicamente em formato de livro, os resultados do encontro "O jogo do livro infantil", bem como as publicações resultantes do GT Literatura infantil e juvenil da ANPOLL.

Além dos trabalhos coletivos, alguns escritores, como Ana Maria Machado, se aventuram na publicação teórica resultante de seus diálogos com os professores em diferentes conferências no país e no exterior, como os as obras publicadas de Machado de 2001 e 2002. Desse modo, as publicações de cunho historiográfico vão rareando em prol de análise de títulos de autores específicos.

Além das constantes reedições dos livros de cunho historiográfico publicados nas décadas de 1980 e 1990, destacamos, neste período, as publicações de Fátima Minguez (2000), Regina Zilberman (2005) e José Nicolau Gregorin Filho (2009), que a partir da análise crítico-teórico apresentam um viés histórico de contextualização. 
O livro Nas arte-manhas do imaginário infantil (2000) é o resultado de projeto de pesquisa desenvolvido na UFRJ por Fátima Minguez que buscou integrar a universidade e a escola de ensino básico. Dividido em cinco capítulos, Minguez reflete sobre a prática literária no espaço escolar, trazendo à cena a produção literária de diferentes escritores brasileiros vinculados a prosa e poesia. No capítulo quatro, a autora descreve as possibilidades de leitura de textos literários na escola a partir de "Rotas de leitura" que fujam de práticas leitoras utilitaristas.

Em Como e porque ler a literatura infantil brasileira ${ }^{13}$ (2005), Regina Zilberman desenvolve, em quinze capítulos, a análise de livros de literatura infantil brasileira das origens do final do século XIX a década de 1980, enfatizando os autores e títulos mais representativos.

José Nicolau Gregorin Filho, em Literatura infantil: múltiplas linguagens na formação leitora (2009) apresenta, em dez partes, vários aspectos da literatura infantil e juvenil brasileira: percurso histórico, concepção de infância e literatura infantil, focalizando a literatura infantil na sala de aula.

Em Portugal, logo em 2001, veio a lume uma edição atualizada (até ao ano 2000) da Breve História da Literatura

13 Em 2014 o livro recebeu uma edição revista e ampliada com a inserção do capítulo 16 que discute a literatura juvenil contemporaneíssima (2008-2013). 
para Crianças em Portugal, de Natércia Rocha, onde a autora completa, com novos dados, sobretudo autores e obras, mas também fenómenos de legitimação e valorização, o seu volume dos anos de 1980, convertendo-se numa das principais figuras de referência dos estudos da LIJ em Portugal, graças igualmente ao seu envolvimento e várias iniciativas, nomeadamente os Prêmios Gulbenkian, e à sua publicação de crítica na imprensa periódica generalista e especializada. Os trabalhos mais ou menos pioneiros de Natércia Rocha, pelo menos em termos de profundidade e continuidade, foram seguidos por outros estudiosos que, de forma mais esporádica, como António Garcia Barreto ou Sérgio Guimarães de Sousa, ou continuada, como José António Gomes, preencheram a década. No caso do primeiro, veja-se a publicação do Dicionário de Literatura Infantil Portuguesa (2002), colmatando um vazio notório a este nível e não mais atualizado desde então. O segundo deu à estampa um estudo, Teoria Breve da Literatura Infantil, que, apesar da brevidade, reflete sobre as especificidades do sistema literário infantil e da semiose que lhe está associada, reconhecendo-lhe, contudo, a par de todas as características do texto literário, a particularidade do seu destinatário específico, sem que isso diminua, por si só, as suas qualidades estéticas. 
Em áreas específicas, nomeadamente a literatura juvenil e as relações entre a literatura tradicional e a LIJ, merecem destaque, respetivamente, os trabalhos monográficos que resultaram de investigações conducentes ao grau de Doutoramento, de Francesca Blockeel, Literatura Juvenil Portuguesa Contemporânea: Identidade e Alteridade (2001), de Maria da Natividade Pires, Pontes e Fronteiras. Da Literatura tradicional à literatura contemporânea (2005), e de Glória Bastos, O Teatro para Crianças em Portugal - História e Crítica (2006). No caso do volume de Francesca Blockeel, destaque-se o relevo que a autora concede à literatura juvenil, que estuda de forma detalhada, sobretudo a partir do 25 de Abril de 1974, habitualmente afastada dos estudos teórico-críticos em Portugal ou incluída, sem especificação, no âmbito dos realizados sobre a literatura infantil. E ainda que, depois, se dedique ao estudo da questão da identidade, o seu panorama histórico percorre diferentes gêneros e temas, continuando, até hoje, a ser a única monografia dedicada especificamente à literatura juvenil portuguesa.

Aliás, a década foi pródiga no surgimento de obras de referência nos estudos críticos da LIJ, fruto do crescimento da investigação na área, da inclusão da disciplina em cursos de graduação e pós-graduação, na área do ensino, dos estudos editoriais, da promoção da leitura, mas também em cursos 
de letras e humanidades. A criação de redes de investigação internacionais, a publicação, com algumas interrupções, da Revista Malasartes [Cadernos de Literatura para a infância e juventude], em duas séries, sob a direção de José António Gomes, referência central dos estudos em Portugal na área, foram alguns dos contributos mais assinaláveis de uma década que viu surgir também as publicações regulares de Sara Reis da Silva (2013), Ana Margarida Ramos (2012) e Fernando Fraga de Azevedo (2006), este último mais no domínio do ensino da LIJ. Destaque-se, ainda, a publicação de uma coleção de crítica e teoria especificamente dedicada ao estudo da LIJ, "Percursos da Literatura Infantojuvenil", da editora Tropelias \& Companhia, iniciada em 2010, e que conta já com onze volumes, incluindo autores como José António Gomes, Sara Reis da Silva, Ana Margarida Ramos, João Manuel Ribeiro, entre outros.

\section{ONDE SE FECHA ESTE TEXTO - ABERTO A OUTRAS ESCRITAS}

Apesar de algumas alusões esporádicas, para esta leitura comparativa não incluímos reflexões de escritores, livros organizados, atas/anais, livros sobre gêneros específicos, leituras e análises parcelares, dedicados a autores, temas ou correntes, nem teses ou trabalhos acadêmicos, mesmo se publicados em livro. 
O interesse crescente pelos estudos literários destinados à infância é uma constatação nos dois países. Verifica-se que, tanto no Brasil como em Portugal, a relação dos estudos teóricos com a formação de professores é uma constante e a produção teórica cresceu à medida que os estudos acadêmicos e os programas curriculares de formação foram incluindo a LIJ. No Brasil, nas décadas de 1950 e 1960, as publicações tinham como destino os professores em nível de formação secundária, Curso Normal; nas décadas de 1980 e 1990, as publicações têm como alvo a formação de professores nos cursos de graduação, em particular nas licenciaturas de Letras e Pedagogia e a partir daí vinculados também aos Programas de Pós-Graduação. As coletâneas e organizações de livros e periódicos sobre a temática são dados anunciados no período em análise e de forte tendência de continuidade.

Na década de 1970 e 1980, em paralelo ao interesse teórico pela produção para crianças e jovens, assiste-se a um acréscimo na produção e circulação de livros infantis, bem como a criação de Associações, Grupos de Pesquisas, eventos específicos sobre a temática, entre outros. Os avanços tecnológicos também contribuíram para a circulação de pesquisas em publicações online, propalando o acesso e intercâmbio entre pesquisadores nacionais e estrangeiros. 
Ceccantini (2004, p.30) afirma que, além "[...] dos grandes panoramas históricos, no entanto, está quase tudo ainda por ser feito no campo dos estudos da literatura infantojuvenil no Brasil", no entanto, podemos dizer que, no campo do panorama histórico, ainda temos muito a fazer, retomando a trilha já percorrida. Por exemplo, a ampliação e atualização do panorama efetivado por Lajolo e Zilberman ou do Dicionário Crítico, de Nelly Novaes Coelho. Refira-se a ausência, também em Portugal, de volumes que atualizem as Histórias já clássicas da LIJ ou o dicionário existente, uma vez que os estudiosos centram a sua atenção no estudo de autores, gêneros ou temas específicos.

Contata-se que em ambos os países uma evolução da abordagem da LIJ realizada que, além de dar relevo à componente formativa da LIJ, passou a estudá-la como fenômeno literário de pleno direito, trabalhando as qualidades estéticas e artísticas e o crescente interesse pelo estudo da ilustração.

Por ora fechamos este texto, mesmo sabendo da sua incompletude, com a certeza de novas visitas aos livros aqui levantados e a retomada de outros que por certo ficaram pelo caminho. 


\section{REFERÊNCIAS:}

Aguiar e Silva, Vítor Manuel (1981). Nótula sobre o conceito de Literatura Infantil. In Guimarães de Sá. Literatura Infantil em Portugal (p. 9-15). Braga: Editorial Franciscana.

Azevedo, Fernando Fraga de. (2006). Literatura infantil e leitores: da teoria às práticas. Braga: Instituto de Estudos da Criança.

Barreto, António Garcia (1998). Literatura para crianças e jovens em Portugal. Porto: Campo das Letras.

. (2002). Dicionário de Literatura Infantil Portuguesa. Porto:

Campo das Letras.

Bastos, Glória (1999). Literatura Infantil e Juvenil. Lisboa: Universidade Aberta.

. (2006). O Teatro para Crianças em Portugal - História e Crítica.

Lisboa: Caminho.

Blockeel, Francesca (2001). Literatura Juvenil Portuguesa Contemporânea: Identidade e Alteridade. Lisboa: Caminho.

Carvalho, Bárbara Vasconcelos (1961). Compêndio de Literatura Infantil. São Paulo: Leia.

Ceccantini, João Luis (Orgs.) (2004). Leitura e literatura infanto-juvenil: memória de Gramado. São Paulo/Assis: Cultura Acadêmica/ANEPAssociação Núcleo Editorial Proleitura.

Coelho, Nelly Novaes (1981). A literatura infantil. História - teoria - análise (Das origens orientais ao Brasil de hoje). São Paulo/Brasília: Quiron.

. (1995). Dicionário crítico da literatura infantil e juvenil brasileira.

São Paulo: EDUSP. . (2000). A literatura infantil. Teoria - análise - didática. São Paulo: Moderna.

Correia João David Pinto (1973). A Literatura Juvenil em Portugal. Lisboa: Ministério da Educação Nacional - Direcção Geral da Educação Permanente. 
(1978). Literatura Juvenil / Paraliteratura. Lisboa: Livraria Novidades Pedagógicas.

Costa, Maria José (1992). Um continente poético esquecido: as rimas infantis.Porto: Porto Editora.

Cunha, Maria Antonieta Antunes (1986). Como Ensinar Literatura Infantil. São Paulo: Editora Bernardo Álvares.

Cunha, Maria Antonieta Antunes (1994). Literatura infantil: teoria \& prática (13a ed.). São Paulo: Ática.

Debus, Eliane S. D. (1996). Entre vozes e leituras: a recepção da literatura infantil e juvenil. (Dissertação de Mestrado). Florianópolis: UFSC.

Diogo, Américo António Lindeza (1994). Literatura Infantil - História, Teoria, Interpretações. Porto: Porto Editora.

Góes, Lúcia Pimentel (1984). Introdução à literatura infantil e juvenil. São Paulo: Pioneira.

Gomes, Alice (1979). A literatura para a infância. Lisboa: Torres \& Abreu.

Gomes, José António (1998). Para uma História da Literatura Portuguesa para a Infância e a Juventude. Lisboa: Ministério da Cultura - Instituto Português do Livro e das Bibliotecas.

Gregorin Filho, José Nicolau (2009). Literatura infantil: múltiplas linguagens na formação de leitores. São Paulo: Melhoramentos.

Lajolo, Marisa, \& Zilberman, Regina (1986). Um Brasil para crianças: para conhecer a literatura infantil brasileira - história, autores e textos. São Paulo: Global.

. (1987). Literatura infantil brasileira: histórias e histórias. São Paulo: Ática.

Lajolo, Marisa (1982). Usos e abusos da Literatura na escola: Bilac e a literatura escolar na República Velha. Rio de Janeiro: Globo.

Lemos, Esther (1972). A Literatura Infantil em Portugal. Lisboa: Ministério da Educação Nacional - Direcção Geral da Educação Permanente.

Machado, Ana Maria (2001). Texturas: sobre leitura e escritos. Rio de Janeiro: Nova Fronteira. . (2002). Como e porque ler os clássicos universais desde cedo. 
Rio de Janeiro: Objetiva.

Meireles, Cecília (1984). Problemas da literatura infantil (4a ed.). Rio de Janeiro: Nova Fronteira.

Minguez, Fátima (2000). Nas artes-manhas do imaginário infantil: o lugar da literatura na sala de aula. Rio de Janeiro: Zeus.

Oliveira, Fernando Rodrigues de. (2010). O ensino da literatura infantil em Compêndio de literatura infantil: para o 3o ano normal (Dissertação de Mestrado. UNESP/Marília). In Bárbara Vasconcelos de. Carvalho. Compêndio de literatura infantil: para o $3^{\circ}$ ano normal. São Paulo: Companhia Editora Nacional.

Perrotti, Edmir (1986). O texto sedutor na literatura Infantil. São Paulo: Ícone.para crianças e adolescentes. Rio de Janeiro: Nórdica.

Pires, Maria da Natividade Carvalho (2005). Pontes e Fronteiras. Da Literatura Tradicional à Literatura Contemporânea. Lisboa: Caminho.

Pires, Maria Laura Bettencourt (1983). História da Literatura Infantil Portuguesa. Lisboa: Vega.

Pondé, Glória Maria Fialho (1985). A Arte de Fazer Artes: como escrever Histórias para Crianças e Adolescentes. Rio de Janeiro: Nórdica.

Ramos, Ana Margarida (2012). Tendências contemporâneas da literatura portuguesa para a infância e juventude. Porto: Tropelias \& Companhia.

Rocha, Natércia.(1984). Breve História da Literatura para Crianças em Portugal. Lisboa: ICALP. . (1992). Breve História da Literatura para Crianças em Portugal. (2a ed.). Lisboa: Instituto de Cultura e Língua Portuguesa - Ministério da Educação.

. (2001). Breve História da Literatura para Crianças em Portugal (nova edição actualizada até ao ano 2000). Lisboa: Caminho.

Sá, Domingos Guimarães de. (1974). Catálogo de Literatura Infantil. Lisboa: Edição do Secretariado para Juventude. _. (1977) Catálogo de Literatura Juvenil. Braga: Editorial Franciscana. (1981). A literatura infantil em Portugal. Achegas para a sua 
história (2a ed.). Braga: Editorial Franciscana.

Silva, Sara Reis da. (2013). Presença e Significado de Manuel António Pina na Literatura Portuguesa para a Infância e a Juventude, Lisboa: Fundação Calouste Gulbenkian/Fundação para a Ciência e a Tecnologia.

Sousa, Sérgio Paulo Guimarães de. (2000). Teoria breve da literatura infantil, Braga: Irmandades da Galiza e de Portugal.

Traça, Maria Emília.(1992). O fio da memória: do conto popular ao conto para crianças (2a ed.). Porto: Porto Editora.

Veloso, Rui Marques (1994). A obra de Aquilino Ribeiro para crianças imaginário e escrita. Porto: Porto Editora.

Yunes, Eliana, \& Pondé, Glória (1988). Leitura e leituras da literatura infantil. São Paulo: FTD.

Zilberman, Regina (1982). A literatura infantil na escola (2a ed.). São Paulo: Global. . (2005). Como e porque ler a literatura infantil brasileira. Rio de Janeiro Objetiva.

Eliane Debus - Doutora em Teoria da Literatura (PUCRS/2001), professora do Departamento de Metodologia de Ensino, do Centro de Ciências da Educação, da Universidade Federal de Santa Catarina. Líder do grupo de pesquisa Literalise.

Ana Margarida Ramos - Doutora em Literatura (Universidade de Aveiro, 2005), professora auxiliar do Departamento de Línguas e Culturas da Universidade de Aveiro. Investigadora do Centro de Investigação "Didática e Tecnologia na Formação de Formadores" (CIDTFF) da mesma Universidade. 